\title{
Alexis St. Martin - the intrepid guinea pig?
}

\author{
Pedro Luiz Squilacci Leme ${ }^{1}$
}

O objetivo deste texto é apresentar o recorte histórico de um fato pouco conhecido e não explorado por nossa literatura médica, assim como discutir críticas recentes e pouco fundamentadas nos relatos históricos à conduta médica e ética envolvidas, que utilizaram um enfoque do século 139I a fatos ocorridos no século XIX.

O dia Mundial da Saúde Digestiva e também do gastroenterologista é celebrado dia vinte e nove de maio de cada ano. O médico considerado pioneiro da fisiologia gástrica, da gastroenterologia e ainda o primeiro a firmar um documento precursor do termo de consentimento para pesquisa com humanos foi o cirurgião William Beaumont (1785-1853), que serviu o exército Americano como médico do Forte Mackinac, localizado na ilha do mesmo nome, no lago Huron, em Michigan, na fronteira norte do país, que era bastante militarizada na época, porque ações militares a partir do Canadá ainda ocorreram no início do século XIX, mesmo após os Estados Unidos terem declarado sua Independência da Inglaterra em 4 de julho de 1776.

O Forte, inaugurado pelos Ingleses em 1715, foi tomado pelos Americanos em 1796, e foi um ponto de defesa importante durante a Guerra de 1812 (1812 a 1815), entre Americanos e Britânicos aliados aos Índios que habitavam a região.

Dia 6 de junho de 1822, um jovem caçador canadense de origem francesa, então com cerca de 18 anos, chamado Alexis St. Martin (1803?-1880), sofreu um ferimento provocado pelo disparo acidental de espingarda à queima-roupa: "não mais que uma jarda" (menos de um metro), num posto de comércio de peles localizado próximo ao Forte, locais ainda preservados atualmente. O ferimento desafiaria até os experientes cirurgiões de Trauma atuais, descrito, em tradução livre:

"A carga... entrou do lado esquerdo do jovem... posteriormente, e em direção oblíqua, para frente e para dentro,

1. Professor Assistente da Faculdade de Ciências Médicas da Santa Casa de São Paulo - Departamento de Cirurgia

Trabalho realizado: Faculdade de Ciências Médicas da Santa Casa de São Paulo - Departamento de Cirurgia

Endereço para correspondência: Pedro Luiz Squilacci Leme. Faculdade de Ciências Médicas da Santa Casa de São Paulo - Departamento de Cirurgia. Rua Doutor Cesário Mota Júnior - Vila Buarque, 01221020 - São Paulo, SP - Brasil. Telefone: (11) 33677721. E-mail:gorableme@uol.com.br literalmente arrebentando tegumentos e músculos do tamanho da mão de um homem, fraturando e destruindo a metade anterior da sexta costela, fraturando a quinta, lacerando a porção inferior do lobo esquerdo do pulmão, o diafragma, e perfurando o estômago... Eu o vi vinte e cinco ou trinta minutos após o acidente... uma porção do estômago estava lacerada... e derramando a comida que ele havia ingerido no café da manhã, através de um orifício grande o suficiente para caber o dedo indicador...".

William Beaumont ainda relatou a herniação de parte do pulmão esquerdo pelo ferimento, do tamanho do ovo de uma perua, (equivalente ao tamanho da palma da mão), que possivelmente protegeu a vítima de um pneumotórax aberto, provocado por esta toracotomia traumática em ferimento toracoabdominal complexo. Embora sem esperança de que houvesse recuperação, Beaumont tratou a ferida do jovem caçador, posteriormente realizou uma sangria e administrou catártico. A evolução foi difícil, St. Martin apresentou infecção local, secreção fétida, febre muito alta por dez dias, dificuldade respiratória, tosse "angustiante" e escape de ar a cada inspiração; por dezessete dias toda a comida ingerida saía pela fístula gástrica, sendo utilizada a opção da época: "... and the only way of sustaining him was by means of nutricious injections per anus...".

Após este período "a comida permaneceu no estômago e o intestino voltou a funcionar", com eliminação de melena, descrita de forma que poderia ser utilizada atualmente: "... a very hard, black, fœetid stool was procured, followed by several similar ones; after which the bowels became quite regular, and continued so".

A recuperação continuou lenta no decorrer do mês; a leitura do relato completo do tratamento mostra que já existiam conceitos estabelecidos sobre inflamação e granulação dos tecidos, mesmo o ferimento tendo ocorrido três meses antes da nossa proclamação da Independência, em setembro de 1822 . O restante do ano e o início do próximo ano foram empregados para o longo processo de curativos, drenagem de abscessos, retirada de fragmentos do projétil, de corpos estranhos, ressecção de parte das costelas e cartilagens costais lesadas, até a cicatrização da ferida. O cirurgião cogitou tentar fechar cirurgicamente a fístula gástrica labiada, mas considerou a vontade do paciente:

"Depois de tentar todos os meios ao meu alcance por oito ou dez meses para fechar o orifício, ao estimular uma inflamação para aderir os lábios da ferida, sem a menor apa- 
rência de sucesso, desisti por ser impraticável de qualquer outra maneira que não fosse a de incisar e juntá-los por suturas; uma operação à qual o paciente não se submeteria".

Exatamente um ano após, em junho de 1823, o ferimento estava cicatrizado, com exceção de uma abertura com cerca de duas e meia polegadas no estômago, por onde constantemente saía a comida ingerida; em maio de 1825 Beaumont iniciou seus experimentos, descritos ainda em tradução livre:

"Quando ele deita sobre o lado oposto, eu posso olhar diretamente a cavidade do estômago, observar seu movimento e quase ver o processo de digestão - Eu posso despejar água com um funil, ou colocar comida com uma colher, e retira-los com um sifão. Eu frequentemente recupero uma suspensão de carne crua e assada e outras substâncias pelo orifício, para determinar o tempo necessário para digerir cada; e uma vez utilizei um plugue de carne crua... no orifício, e descobri que em menos de cinco horas estava completamente digerido...".

Beaumont mudou-se para outros postos militares, em outros estados, levando St. Martin, mas em agosto do mesmo ano (1825), este voltou para o Canadá, onde permaneceu por quatro anos, casou-se e teve dois filhos. Em agosto de 1829 o médico conseguiu traze-lo, juntamente com a família, para Forte Crawford, Wisconsin, na parte norte do rio Mississipi, uma distância próxima de 2.000 milhas (mais de 3.000 quilometros): "After considerable difficulty, and at great expense to me...".

Alexis St. Martin começou a trabalhar para ele como servo e os experimentos recomeçaram, sendo mantidos entre agosto de 1829 e março de 1831, período em que teve mais filhos. Na primavera de 1831, o paciente decidiu voltar com a família para o Canadá, em uma canoa aberta, seguindo o rio Mississipi, passando por St. Louis, subindo o rio Ohio, percorrendo os lagos Erie e Ontário, seguindo o rio São Lourenço até Montreal, chegando em junho e permanecendo com sua família até outubro de 1832, sem serem afetados com uma epidemia de cólera que atingiu o Canadá na época.

Em novembro de 1832, agora sem a família, reencontrou pela terceira vez o Dr. Beaumont e as experiências continuaram até março de 1833 em Washington, com apoio do chefe do Departamento Médico do Exército, mas há relatos de que St. Martin recebeu a notícia da morte de um dos filhos, retornando definitivamente para o Canadá. Beaumont publicou parte de seus estudos em 1825 e 1826, mas apenas em 1833 seu estudo clássico: "Experiments and Observations on the Gastric Juice, and the Physiology of Digestion"(1), a pesquisa mais importante sobre a fisiologia da digestão já realizada até então, considerando as condições primitivas da época; sua publicação, disponível na íntegra por meios eletrônicos, teve pouca repercussão nos Estados Unidos por falta de estudiosos sobre o assunto, mas foi traduzida para o alemão em 1834.
Existe uma pequena diferença do período citado por Beaumont, novembro de 1832, e o primeiro contrato firmado em cartório entre o médico e o paciente, 19 de outubro de 1832. Os originais dos contratos podem ser encontrados em Archives, Wahington University School of Medicine, em St. Louis, Missouri, datados em 1832 e 1833, assim como recibos de valores pagos ao paciente, que era analfabeto, descritos nas palavras de Ira Rutkow, um grande pesquisador sobre história da Cirurgia, em Arch Surg. 1998; 133 (11): 1259(2)

"Uma das peças mais intrigantes da cirurgia Americana: as últimas páginas de um contrato datado de 19 de outubro de 1832, entre William Beaumont e Alexis St. Martin (sua marca " $X$ "), concedendo o uso do estômago deste último para propósitos experimentais. Na parte inferior, estão confirmados os pagamentos a St. Martin, no valor de US \$107. Esse registro é único porque representa a primeira instância documentada nos Estados Unidos de quando a preocupação com o bem-estar do paciente foi demonstrada. Além disso, representa o reconhecimento de que a experimentação humana foi obtida em escrita formal com consentimento informado."

Questiona-se que St. Martin era uma pessoa rude, inculta e iletrada, talvez compelida a firmar com " $X$ " os contratos e recibos, mas os valores são significativos, se considerarmos que o salário de um cirurgião do Exército Americano nos anos 1800 era de cerca de US \$ 30 por mês. Os conceitos de Bioética e Ética em Pesquisa não existiam na época, assim como os documentos têm a forma de contratos de cartório, mas representam um grande avanço considerando a mentalidade e os costumes do século XIX.

Argumenta-se que o paciente permitiu a realização dos experimentos não como retribuição pelo tratamento médico que salvou sua vida, mas por conta do contrato firmado. Tal afirmação não encontra respaldo cronológico, uma vez que os primeiros estudos, publicados em 1825 e 1826, foram bem anteriores aos contratos (1832 e 1833). Obviamente, pela visão atual, um analfabeto pode não ser considerado adequado como sujeito de uma pesquisa tão importante, mas se considerarmos que foram guardados também os recibos e o paciente os marcou com o mesmo " $\mathrm{X}$ ", podemos inferir que houve anuência.

Critica-se o Dr. Beaumont por ter contratado inicialmente o paciente como servo, e este ter realizado atividades domésticas como cortar lenha e carregar pesos, mas esta foi mais uma providencial intervenção do médico, uma vez que ainda na fase de recuperação, quando havia preocupação com o tratamento e não com a pesquisa, cerca de dez meses após o ferimento, as autoridades do município determinaram que St. Martin, descrito como "... miserável e indefeso", fosse declarado "indigente comum" ("common pauper") e "... porque eles não eram nem capazes nem obrigados a cuidar 
dele, iriam mandá-lo... para o lugar onde nasceu". Considerando que a longa viagem de canoa até o Canadá poderia determinar a morte do jovem, o médico o acolheu em sua própria casa, permitindo a cicatrização final dos ferimentos.

Devemos considerar que o paciente deixou o médico em 1825, embora sem seu consentimento, três meses após o início dos experimentos: “... he returned to Canada, his native place, without obtaining my consent.". Após um segundo período nos Estados Unidos, retornou para seu país com a família, depois de um ano e sete meses trabalhando com o médico, e foi auxiliado por ele para equipar a canoa usada para transportar seus familiares: "... and gave him an outfit for himself, wife and children". O contrato para permitir os experimentos e o pagamento específico para esta finalidade, só foi firmado em 1832 e em maio de 1833. Cinco meses após o início da terceira fase dos experimentos, St. Martin retornou definitivamente ao Canadá, mesmo durante a vigência do contrato.

Questiona-se que o Dr. Beaumont "cientista" começou a suplantar o Dr. Beaumont "médico" quando este não planejou uma operação para corrigir a fístula gástrica, embora exista referência a esta opção ainda em 1823. O texto não é claro se o doente não se submeteria à operação por decisão própria ou do médico: "... I gave it up as impracticable in any other way than that of incising and bringing them together by sutures; an operation to which the patient would not submit". Devemos considerar que este procedimento, se realizado, ocorreria em condições precárias e ainda sem anestesia (o primeiro procedimento operatório com anestesia inalatória só foi realizado em 1846). O verdadeiro milagre de St. Martin ter sobrevivido poderia ter sido revertido com esta intervenção.

Seguramente alguns experimentos foram desconfortáveis: "O menino se queixou de alguma dor e desconforto no peito." Outros sintomas referidos por St. Martin durante os estudos foram sensação de peso e "angústia" no epigástrio, ligeira vertigem e escurecimento da visão, principalmente quando pequenos sacos de tecido com alimentos foram introduzidos e depois retirados do estômago. Alguns alimentos também eram amarrados com fios de seda para serem recuperados posteriormente pela fístula.

Argumenta-se ainda que não houvesse um questionamento da própria ética e que o médico havia se "inebriado com o enorme prestígio que esta fistula gástrica havia the proporcionado, destacando-o como fisiologista e com o lugar permanente que alcançou na história da pesquisa". Afirmações extremamente injustas podem ser lidas em textos sobre o assunto, comparando o médico a um mecânico capaz de consertar um motor, mas que não trocou um pneu furado, ou a um cirurgião cardíaco, que após operar o coração, deixaria o tórax aberto por quase sessenta anos apenas para ver o funcionamento do órgão. Os comentários são lamentáveis, assim como o argumento do advogado de um assassino (Darnes-Davis murder case), cuja vítima (o editor de um jornal), foi tratada entre outros pelo Dr. Beaumont em 1840, que realizou uma trepanação, procedimento habitual na época, na vítima de agressão com um cano de ferro. $\mathrm{O}$ advogado tentou colocar a culpa da morte não no agressor, (um político inconformado com os editoriais do jornalista), mas nos médicos que efetuaram o tratamento, e que o Dr. Beaumont havia colocado seus "interesses científicos sobre o bem-estar de um paciente": "... it was upon the same principle of curiosity which kept the hole open in the man's stomach thath he bored a hole in Davis' head to see what was going on there!". O desfecho do caso resultou em uma multa de US \$ 500 para o réu, que saiu livre, e "a reputação de Beaumont foi prejudicada em pequena medida".

St. Martin se estabeleceu com a família em uma pequena fazenda no Canadá e enviou cartas ao médico, possivelmente escritas pelo pároco local. Relatos da época reportam que todos eram muito pobres e "destituídos de roupas", surgiram também informações sobre sua inclinação para a bebida. Em carta datada de 19 de dezembro de 1834, relatou ter tentado retornar, mas não ter conseguido e pediu dinheiro para manter a família. Após a morte do Dr. Beaumont (1853), St. Martin, em 1856, foi vítima de um charlatão, "Dr. Bunting", um negociante de má reputação, descrito pela imprensa da época como "impostor, vigarista e vilão", dando início a um ciclo de deploráveis exposições públicas do doente em várias cidades Americanas e Canadenses. Existem relatos em que os médicos que assistiram a estas apresentações concluíram que "Bunting era uma farsa e que o homem de 62 anos com o peito perfurado era um bêbado desolado". Foram descritos planos de apresentá-lo em um circo e mesmo levá-lo à Europa, fatos que possivelmente não ocorreram; embora St. Martin referisse ter estado no velho continente, não existem registros fidedignos que corroborem esta afirmação.

Em 1879, St. Matin estabeleceu-se em St. Thomas de Joliette, local próximo ao de seu nascimento, e manteve correspondência, agora com o filho do Dr. Beaumont (Israel), relatando que estava se tornando velho e doente, assim como estava muito pobre, pedindo por caridade. Informações de um juiz da cidade, que teve contato várias vezes com ele, dão conta de que realmente era bastante pobre e "reclamou amargamente de alguns médicos que o haviam abusado terrivelmente e teve palavras amáveis para outros". Acredita-se que o dinheiro ganho durante suas viagens tenha sido gasto de maneira frívola, "muito viciado em bebida, quase um bêbado pode-se dizer. Ele era um homem alto e magro, com uma pele muito escura, e me pareceu mal humorado". 
Vivendo em uma fazenda pequena, pode-se imaginar as dificuldades para se manter em um país com clima tão inóspito.

Existem dois relatos sobre a morte de William Beaumont, ocorrida aos 68 anos em St. Louis, em 1853; uma versão cita que ele teria escorregado no gelo e morrido das complicações decorrentes de um traumatismo cranioencefálico, outra versão determina que a morte ocorreu em função de uma fratura da bacia. Alexis St. Matin faleceu dia 24 de junho de 1880; para evitar a curiosidade de pessoas que quisessem realizar uma necrópsia ilícita, sua família deixou seu corpo se decompor e só realizou o sepultamento em túmulo mais profundo que o habitual e não marcado quatro dias após (28 de junho). O serviço religioso católico teve que ser realizado com o cadáver do lado de fora da igreja, em função do estado de putrefação. Apenas em 1962 a Sociedade Canadense de Fisiologia erigiu uma placa em sua homenagem no cemitério da paróquia de Saint Thomas, em Joliette, Quebec, mas não foi possível determinar o local exato da sepultura.

Existem referências a outro precursor da gastroenterologia, Ismar Isidor Boas (1858-1938). Nascido na Polônia, estudou na Alemanha, tendo se destacado em patologia, fisiologia da digestão e descrito o Lactobacillus acidophilus no suco gástrico de pessoas com carcinoma do estômago. Ismar Boas abriu a primeira clínica especializada em gastroenterologia em Berlim (1886), fundou o primeiro Jornal Médico dedicado à especialidade (1895) e a Sociedade Germânica de Gastroenterologia (1913). O médico, clinicando em Viena, teve morte trágica ao se suicidar quando os nazistas cassaram sua licença para exercer a profissão. Suas contribuições foram significativas, mas seu nascimento só ocorreu cinco anos após a morte de William Beaumont, que recebeu o crédito de autores consagrados como Lyons e Petrucelli, que consideraram o início da moderna gastoenterologia na manhã de 6 de junho de 1822. Beaumont provou a presença de ácido clorídrico no estômago, estabeleceu a relação do estado emocional com a secreção gástrica e a digestão, assim como delineou detalhes da motilidade gástrica. Estima-se que só surgiram estudos com esta magnitude com Ivan Pavlov (1849-1936), na Rússia, que realizou experimentos com animais.

Sir William Osler (1849-1919), também ressaltou em 1902 as contribuições mais importantes do livro de 280 páginas, publicado por Beaumont aos 48 anos. Dividido em duas seções, a primeira contendo observações gerais sobre vários tópicos em gastroenterologia; as palavras dispepsia, gastrite, citações sobre inervação gástrica e do sistema nervoso interferindo nas sensações de fome e sede podem ser encontradas no texto. A segunda parte contém a descrição de 238 experimentos e inclui 51 inferências finais; podemos notar ainda a variedade e quantidade de alimentos que St. Martin recebeu durante os estudos. Osler enumerou as contrubuições mais importantes do texto: (1) uma descrição mais precisa e completa do suco gástrico; (2) confirmação da observação prévia de que o ácido clorídrico era o ácido importante do suco gástrico; (3) reconhecimento de que suco gástrico e muco eram secreções separadas; (4) estabelecimento da influência do estado emocional na secreção do suco gástrico e digestão; (5) uma comparação mais precisa e completa da ação do suco gástrico dentro e fora do estômago; (6) refutação de muitas opiniões erradas; (7) o primeiro estudo abrangente de movimentos do estômago; e (8) uma tabela da digestibilidade de diferentes itens da dieta.

Devemos valorizar o pioneirismo do cirurgião Norteamericano, considerando a época em que ocorreram as pesquisas e a ausência de laboratórios, que obrigavam o pesquisador a utilizar o próprio paladar para definir alguns parâmetros:

"... On applying the tongue to the mucous coat of the stomach, in its empty, unirritated state, no acid taste can be perceived. When food, or other irritants, have been applied to the villous membrane, and the gastric papillæ excited, the acid taste is immediately perceptible. These papillæ, I am convinced, from observation, form a part of what is called by authors, the villi of the stomach..."

A descrição de Osler, publicada em 1902 (JAMA. 1902; 39: 1223-31)(3), deve ser avaliada pela beleza e erudição do texto:

"Venha comigo por alguns momentos em um lindo dia de junho em 1822, até as longínquas regiões selvagens do norte, até a Ilha de Michilimacinac, onde as águas do Lago Michigan e do Lago Huron se unem e onde fica o Forte Mackinac, rico em memórias de índio e voyageur,..." (do francês, significa barqueiro) "... um dos quatro postos importantes nos lagos superiores nos dias em que a rosa e a flor-de-lis lutavam pelo dominio do mundo ocidental... Suas paliçadas e casas de bloco ecoaram os gritos de guerra de Ojibwas e Ottawas, de Hurons e Iroqueses, e o antigo forte tinha sido palco de massacres sangrentos e batalhas dificeis..."

William Osler publicou ainda um estudo sobre Beaumont entitulado "A Backwoods Physiologist" (Um Fisiologista do Interior); se levarmos em conta as dificuldades enfrentadas na época, os locais inóspitos e inadequados à pesquisa como as instalações militares, podemos avaliar a importância e o pioneirismo de William Beaumont na História da Medicina.

\section{Referências}

1. Beaumont W. Experiments and observations on the gastric juice, and the physiology of digestion. Plattsburgh, N.Y: F.P. Allen; 1833. 280p. 
2. Rutkow IM. Beaumont and St Martin: a blast from the past. Arch Surg. 1998; 133(11):1259.

3. Osler W. William Beaumont. A pionner American physiologist. JAMA. 1902; 39(20): 1223-31.

\section{Bibliografia}

Cappell MS. The effect of Nazism on medical progress in gastroenterology: the inefficiency of evil. Dig Dis Sci. 2006; 51(6): 1137-58. Helms R. Alexis St. Guinea Pig Zero: an Anthology of the Journal for Human Research Subjects. New Orleans: Garrett County Press; 2002. 245p.

Hoenig LJ, Boyle JD. The life and death of Ismar Boas. J Clin Gastroenterol. 1988; 10(1): 16-24.
Lyons AS, Petrucelli RJ. Medicine: an illustrated history. New York: Abrams; 1987.

Roberts CS. William Beaumont, the Man and the Opportunity. In: Walker HK, Hall WD, Hurst JW, editors. Clinical Methods: The History, Physical, and Laboratory Examinations. $3^{\text {rd }}$ ed.[monography online]. Boston: Butterworths; 1990. Available from: https: / /www. ncbi.nlm.nih.gov/books/NBK459/ [2018 23 Jun]

Rutkow IM. Surgery: an illustrated history. St. Louis: Mosby; 1993. 564p.

Rutkow IM. American surgery an illustrated history. Philadelphia: Lippincott-Raven; 1998. 638p.

Trabalho recebido: $16 / 07 / 2018$

Trabalho aprovado: 20/07/2018 